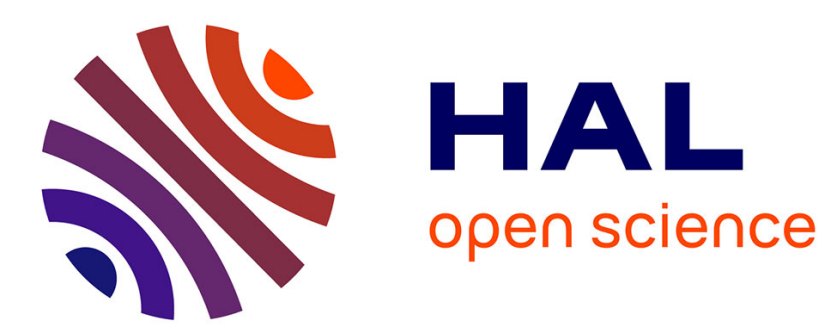

\title{
Robustness of Closed-Loop Control to Biodiversity: a Didactic Example
}

Francis Mairet, Olivier Bernard

\section{To cite this version:}

Francis Mairet, Olivier Bernard. Robustness of Closed-Loop Control to Biodiversity: a Didactic Example. 19th IFAC World Congress, Aug 2014, Cape Town, South Africa. pp.5321-5326, 10.3182/20140824-6-ZA-1003.02193 . hal-01094693

\section{HAL Id: hal-01094693 \\ https://inria.hal.science/hal-01094693}

Submitted on 12 Dec 2014

HAL is a multi-disciplinary open access archive for the deposit and dissemination of scientific research documents, whether they are published or not. The documents may come from teaching and research institutions in France or abroad, or from public or private research centers.
L'archive ouverte pluridisciplinaire HAL, est destinée au dépôt et à la diffusion de documents scientifiques de niveau recherche, publiés ou non, émanant des établissements d'enseignement et de recherche français ou étrangers, des laboratoires publics ou privés. 


\title{
Robustness of Closed-Loop Control to Biodiversity: a Didactic Example ${ }^{\star}$
}

\author{
Francis Mairet* Olivier Bernard* \\ * Inria Biocore, BP93, 06902 Sophia-Antipolis Cedex, France (e-mail: \\ francis.mairet@inria.fr)
}

\begin{abstract}
Single-species models are generally used for the design of bioprocess control laws. Nonetheless, most of the bioprocesses, if not all, involve an important biodiversity (different species or mutants). Here we propose to define and study the multispecies robustness of bioprocess control laws: given a control law designed for one species, what happens when two or more species are present? We illustrate our approach with a control law which regulates substrate concentration using measurement of growth activity. Depending on the properties of the additional species, the control law can lead to the correct objective, but also to an undesired monospecies equilibrium point, coexistence, or even a failure point.
\end{abstract}

Keywords: Biotechnology, stability analysis, nonlinear systems, bioreactor, multispecies, coexistence.

\section{INTRODUCTION}

Most of the bioprocesses, if not all, involve an important biodiversity, even when a single microorganism is initially targeted. This diversity, desired or endured can involve different species (e.g. in anaerobic digestion) or, for one species, different strains initially present or resulting from natural mutation within the process (e.g. in pharmaceutical biotechnology). Nevertheless, theoretical developments in automatic control of bioprocesses are generally based on the single-species dogma (one macroscopic reaction involves one species). A few works have shed light on the importance of biodiversity for the modelling and control of bioprocesses. For example, the effect of multispecies has been shown in simulation for anaerobic digestion [Ramirez et al. 2009]. It has also been tackled in the development of optimal strategies (via simulation for the start-up of an anaerobic digester [Sbarciog and Vande Wouwer 2012] and analytically for fed-batch operation [Gajardo et al. 2008]).

Classically, robustness of control laws are considered with respect to parameter uncertainties or noise measurements, but to our knowledge, never to the presence of other species. Indeed, given a control law designed for one species, what happens when two or more species are actually present? To tackle this problem, we introduce the concept of multispecies robustness. A control law is said multispecies robust for a given set of species if the performance of the control law (in a sense that will be defined later) is not affected by the presence of any species from this set.

To define the multispecies robustness of a control law, one should study the asymptotic behavior of a system including several species competing for a substrate. This has been widely done in mathematical ecology in order to study the competition of species [Smith and Waltman

\footnotetext{
* This work benefited from the support of the Facteur 4 research project founded by the French National Research Agency (ANR).
}

1995]. When a constant dilution rate is applied, the principle of competitive exclusion states that at most one species will survive. On the other hand, De Leenheer and Smith [2003], Gouzé and Robledo [2005], Mazenc et al. [2008] have proposed control laws in order to obtain coexistence. Finally, recent developments have been proposed for the selection of species [Mairet et al. 2013, Bayen and Mairet 2014]: here, the objective is to design a control strategy in order to select a species of interest. These papers propose some useful tools for studying multispecies robustness.

To illustrate our approach, we study the multispecies robustness of a control law proposed in Mailleret et al. [2004] in order to regulate substrate concentration. Depending on the properties of the additional species, the control law can lead to the correct objective, but also to an undesired monospecies equilibrium point, coexistence, or even a failure point.

\section{FRAMEWORK AND DEFINITION}

We consider a classical model of micro-organism growth limited by one substrate in a chemostat [Dochain 2008]. Given $x_{1}$ and $s$ the concentrations of biomass and substrate respectively, the model writes:

$$
\left\{\begin{array}{l}
\dot{s}=u(t)\left(s_{i n}-s\right)-k_{1} \mu_{1}(s) x_{1} \\
\dot{x_{1}}=\left(\mu_{1}(s)-u(t)\right) x_{1}
\end{array}\right.
$$

where $u(t)$ is the dilution rate, $s_{i n}$ is the input substrate concentration and $k_{1}$ is the pseudo yield coefficient.

Hypothesis 1 . The specific growth rate $\mu_{1}(s)$ is a nonnegative $\mathcal{C}^{1}$ function with $\mu_{1}(0)=0$.

A species is defined by a parameter vector $\theta \in S \subset \mathbb{R}_{+}^{n_{\theta}}$, gathering stoechiometric and kinetic parameters (i.e. parameters of the growth rate $\mu$ ). We will refer to $S$ as a set of species. 
We consider a control law which stabilizes the substrate concentration towards a set-point $s^{*}$. By definition, the multispecies robustness of this control law guarantees that, in presence of multispecies, the system (whose state vector is denoted $\xi$ ) will be stabilized at a point $\xi$ with the same or better productivity $\mathcal{P}(\xi)$ than for the set-point in monoculture $\xi^{*}$.

Consider a control law $u(\xi)$ which globally stabilizes System (1) towards the set-point $s^{*}$.

Definition 1. The control law $u(\xi)$ is said to be $(S, n, \mathcal{P})$ robust iff, for any $n$ species $x_{i}, i=2, \ldots, n+1$ such that $\theta_{i} \in S$, the control law globally stabilizes the system:

$$
\left\{\begin{array}{l}
\dot{s}=u(\xi)\left(s_{i n}-s\right)-\sum_{i=1}^{n+1} k_{i} \mu_{i}(s) x_{i} \\
\dot{x}_{i}=\left(\mu_{i}(s)-u(\xi)\right) x_{i}, \quad i=1,2, \ldots, n+1 .
\end{array}\right.
$$

towards a point $\hat{\xi}$ such that $\mathcal{P}(\hat{\xi}) \geq \mathcal{P}\left(\xi^{*}\right)$, where $\xi^{*}=$ $\left(s^{*},\left(s_{\text {in }}-s^{*}\right) / k_{1}, 0, \ldots, 0\right)$.

For example, for wastewater treatment, the productivity criterion is defined as the organic load removed: $\mathcal{P}(\xi)=$ $u(\xi)\left(s_{i n}-s\right)$. This criterion will be considered in the following to illustrate our presentation.

\section{APPLICATION}

To highlight the concept that we introduce, we will consider the control law proposed in Mailleret et al. [2004]. This must be seen as a simple didactic example to introduce the ideas and show their relevance for bioprocess management.

\subsection{Control law design}

In the following, we assume that the measurement of total growth in the bioreactor is available:

Hypothesis 2. We consider that the following measurement is available:

$$
y(\xi)=\sum_{i=1}^{n+1} l_{i} \mu_{i}(s) x_{i}
$$

where $l_{i}$ is the associated yield coefficient for species $i$.

In anaerobic digestion, the methane flow rate can be used given the low solubility of methane (see e.g. Mailleret et al. [2004], Karafyllis et al. [2008]). For other bioprocesses, the total growth can be estimated using observer-based estimator [Bastin and Dochain 1990, Perrier et al. 2000] based on measurement of $\mathrm{O}_{2}$ or $\mathrm{CO}_{2}$ for example.

Given a set-point $s^{*} \in\left(0, s_{i n}\right)$, we consider the feedback law proposed by Mailleret et al. [2004]:

Theorem 3. Under Hypotheses 1 and 2, the feedback control law

$$
u(\xi)=\gamma y(\xi)
$$

with $\gamma=\frac{k_{1}}{l_{1}\left(s_{i n}-s^{*}\right)}$ globally stabilizes System (1) towards the positive set point $\left(s^{*}, x_{1}^{*}\right)$, where $x_{1}^{*}=\left(s_{i n}-s^{*}\right) / k_{1}$.

Proof. See Mailleret et al. [2004].
Robustness of this control law with respect to fluctuations in $s_{i n}$ has been considered in Karafyllis et al. [2008]. Here, we will study its multispecies robustness. For sake of simplicity, we restrict our analyses to the presence of only one additional species with initial conditions $\left(s, x_{1}, x_{2}\right)$ in the attractive invariant manifold $\left\{\left(s, x_{1}, x_{2}\right) \mid s+k_{1} x_{1}+\right.$ $\left.k_{2} x_{2}=s_{i n}\right\}$. Under this hypothesis, System (2) with Control law (3) becomes:

$$
\dot{x_{i}}=\left[\mu_{i}(s)-\gamma \sum_{j=1}^{2} l_{j} \mu_{j}(s) x_{j}\right] x_{i}, \quad i=1,2 .
$$

with $s=s_{i n}-\sum_{i=1}^{2} k_{i} x_{i}$.

\subsection{Equilibria}

System (4) admits the following equilibria:

- Substrate depletion $(s=0)$ :

$E_{0}=\left(x_{1}^{0}, x_{2}^{0}\right)$ such that $k_{1} x_{1}^{0}+k_{2} x_{2}^{0}=s_{i n}$.

This corresponds to an equilibrium line.

- Washout $\left(s=s_{i n}\right)$ :

$E_{w}=(0,0)$.

- Monospecies $1(s=s *)$ :

$E_{1}=\left(x_{1}^{*}, 0\right)$, where $x_{1}^{*}=\frac{1}{\gamma l_{1}}$

- Monospecies 2 :

$$
\begin{array}{r}
E_{2}=\left(0, x_{2}^{*}\right), \text { where } x_{2}^{*}=\frac{1}{\gamma l_{2}} \text { iff } \\
\frac{k_{2}}{l_{2}}<\gamma s_{i n}
\end{array}
$$

The substrate concentration at equilibrium is $s=$ $s_{2}^{*}:=s_{i n}-\frac{k_{2}}{l_{2} \gamma}$. Note that $E_{2}$ exists iff we have $s_{2}^{*}>0$.

- Coexistence : this equilibrium point is possible if the two growth functions have an intersection point:

$$
\begin{gathered}
\exists s_{c} \in\left(0, s_{i n}\right) \mid \mu_{1}\left(s_{c}\right)=\mu_{2}\left(s_{c}\right) . \\
E_{c}=\left(\tilde{x}_{1}, \tilde{x}_{2}\right) \text { where } \\
\left\{\begin{array}{l}
\gamma\left(l_{1} \tilde{x}_{1}+l_{2} \tilde{x}_{2}\right)=1 \\
\left(k_{1} \tilde{x}_{1}+k_{2} \tilde{x}_{2}\right)=s_{\text {in }}-s_{c} .
\end{array}\right.
\end{gathered}
$$

$E_{c}$ exists iff $\tilde{x}_{1}$ and $\tilde{x}_{2}$ are positive, i.e. iff:

$$
\tilde{x}_{1}=\frac{l_{2}\left(s_{c}-s_{2}^{*}\right)}{k_{2} l_{1}-k_{1} l_{2}}>0 \quad \text { and } \quad \tilde{x}_{2}=\frac{l_{1}\left(s_{c}-s^{*}\right)}{k_{1} l_{2}-k_{2} l_{1}}>0 .
$$

These conditions impose that the substrate concentrations of monospecies equilibrium are located on either side of the intersection point of the growth functions:

$$
\begin{aligned}
& \cdot \text { if } \frac{l_{2}}{k_{2}}>\frac{l_{1}}{k_{1}} \text {, then } s^{*}<s_{c}<s_{2}^{*} \text {. } \\
& \cdot \text { if } \frac{l_{1}}{k_{1}}>\frac{l_{2}}{k_{2}} \text {, then } s_{2}^{*}<s_{c}<s^{*} \text { (recalling that } \\
& s_{2}^{*} \leq 0 \text { if } E_{2} \text { does not exist). }
\end{aligned}
$$

For each non-trivial equilibrium $E_{\bullet}$, we denote $\mathcal{P}_{\bullet}$ the corresponding productivity:

$$
\begin{aligned}
& \mathcal{P}_{1}=\mu_{1}\left(s^{*}\right)\left(s_{i n}-s^{*}\right) \\
& \mathcal{P}_{2}=\mu_{2}\left(s_{2}^{*}\right)\left(s_{i n}-s_{2}^{*}\right) \\
& \mathcal{P}_{c}=\mu_{1}\left(s_{c}\right)\left(s_{i n}-s_{c}\right)
\end{aligned}
$$




\subsection{Local stability analysis}

The Jacobian matrix $J$ of System (4) is:

$$
J=\left[\begin{array}{cc}
B_{1}-\gamma\left(y(\xi)+x_{1} A_{1}\right) & -k_{2} \mu_{1}^{\prime}(s) x_{1}-\gamma x_{1} A_{2} \\
-k_{1} \mu_{2}^{\prime}(s) x_{2}-\gamma x_{2} A_{1} & B_{2}-\gamma\left(y(\xi)+x_{2} A_{2}\right)
\end{array}\right]
$$

where

$$
\begin{aligned}
& A_{i}=l_{i} \mu_{i}(s)-k_{i}\left(l_{1} \mu_{1}^{\prime}(s) x_{1}+l_{2} \mu_{2}^{\prime}(s) x_{2}\right), \\
& B_{i}=\mu_{i}(s)-k_{i} \mu_{i}^{\prime}(s) x_{i} .
\end{aligned}
$$

Local stability of $E_{0}$. The eigenvalues of the Jacobian matrix $J$ evaluated at $E_{0}$ are:

$$
\begin{aligned}
& \lambda_{1}=0 \\
& \lambda_{2}=\mu_{1}^{\prime}(0) x_{1}^{0}\left(\gamma s_{i n} l_{1}-k_{1}\right)+\mu_{2}^{\prime}(0) x_{2}^{0}\left(\gamma s_{i n} l_{2}-k_{2}\right) .
\end{aligned}
$$

Given that $\gamma s_{i n} l_{1}>k_{1}, E_{0}$ is unstable if $\gamma s_{i n} l_{2}>k_{2}$, i.e. if $E_{2}$ exists (Condition (C1)). Otherwise, further analysis allows us to conclude that a subspace of $E_{0}$ is locally stable.

Stability of $E_{w}$. At $E_{w}$, the Jacobian matrix $J$ becomes:

$$
J=\left[\begin{array}{cc}
\mu_{1}\left(s_{i n}\right) & 0 \\
0 & \mu_{2}\left(s_{i n}\right)
\end{array}\right]
$$

so $E_{w}$ is unstable.

Local stability of $E_{1}$ and $E_{2}$. The eigenvalues of the Jacobian matrix $J$ evaluated at $E_{1}$ are:

$$
\lambda_{1}=-\mu_{1}\left(s^{*}\right) \text { and } \lambda_{2}=\mu_{2}\left(s^{*}\right)-\mu_{1}\left(s^{*}\right)
$$

Thus, $E_{1}$ is locally stable iff

$$
\mu_{1}\left(s^{*}\right)>\mu_{2}\left(s^{*}\right) .
$$

Similarly, $E_{2}$ is locally stable iff

$$
\mu_{2}\left(s_{2}^{*}\right)>\mu_{1}\left(s_{2}^{*}\right) .
$$

Local stability of $E_{c}$. At the equilibrium point $E_{c}$, the trace and determinant of $J$ writes:

$$
\begin{aligned}
& \operatorname{tr}(J)=-\mu_{1}\left(s_{c}\right)-\gamma \tilde{x}_{1} \tilde{x}_{2}\left[\mu_{2}^{\prime}\left(s_{c}\right)-\mu_{1}^{\prime}\left(s_{c}\right)\right]\left(k_{2} l_{1}-k_{1} l_{2}\right) \\
& \operatorname{det}(J)=\mu_{1}\left(s_{c}\right) \gamma \tilde{x}_{1} \tilde{x}_{2}\left[\mu_{2}^{\prime}\left(s_{c}\right)-\mu_{1}^{\prime}\left(s_{c}\right)\right]\left(k_{2} l_{1}-k_{1} l_{2}\right)
\end{aligned}
$$

Thus, $E_{c}$ is locally stable iff

$$
\left[\mu_{2}^{\prime}\left(s_{c}\right)-\mu_{1}^{\prime}\left(s_{c}\right)\right]\left(k_{2} l_{1}-k_{1} l_{2}\right)>0 .
$$

\subsection{Multispecies robustness}

We now consider the following assumption on the growth functions:

Hypothesis 4. The specific growth rates $\mu_{i}(s)$ are assumed to be of Michaelis-Menten type:

$$
\mu_{i}(s)=\bar{\mu}_{i} \frac{s}{s+K_{i}} .
$$

where $\bar{\mu}_{i}$ and $K_{i}$ are respectively the maximum growth rate and the half-saturation constant.

Remark that only the product/substrate yield coefficient $\alpha_{i}:=l_{i} / k_{i}$ matters to compute local stability and productivity. As a consequence, a species can be defined by the set of three parameters:

$$
\theta_{i}=\left(\bar{\mu}_{i}, K_{i}, \alpha_{i}\right)
$$

and we consider

$$
S:=\left[\bar{\mu}^{-}, \bar{\mu}^{+}\right] \times\left[K^{-}, K^{+}\right] \times\left[\alpha^{-}, \alpha^{+}\right] .
$$

Now, we can try to define the largest set ${ }^{1} S_{R} \subset S$ such that Control law $(3)$ is $\left(S_{R}, 1, \mathcal{P}\right)$ robust.

Proposition 5. Given initial conditions $\left(x_{1}^{0}, x_{2}^{0}\right) \in \mathbb{R}_{+}^{* 2}$ such that $k_{1} x_{1}^{0}+k_{2} x_{2}^{0}<s_{\text {in }}\left(i . e . s^{0}>0\right)$, the asymptotic behavior of System (4) is given in Table 1.

Proof. First, note that System (4) is dissipative: all positive trajectories lie in the bounded set $\left\{\left(x_{1}, x_{2}\right) \in \mathbb{R}_{+}^{2} \mid\right.$ $\left.k_{1} x_{1}+k_{2} x_{2} \leq s_{\text {in }}\right\}$.

If $(\mathrm{C} 1)$ does not hold, a subspace of $E_{0}$ is locally stable (so the control law is not robust). Now, we restrict our analysis to the subset $\left\{\theta \in S \mid \gamma s_{i n} \alpha_{2}>1\right\}$.

Let $z=l_{1} x_{1}+l_{2} x_{2}$. In the coordinates $\left(z, x_{1}\right)$, System $(4)$ becomes:

$$
\left\{\begin{array}{l}
\dot{z}=y(\xi)(1-\gamma z) \\
\dot{x_{1}}=\left(\mu_{1}(s)-\gamma y(\xi)\right) x_{1} .
\end{array}\right.
$$

Given positive initial conditions such that $k_{1} x_{1}^{0}+k_{2} x_{2}^{0}<$ $s_{i n}$, we have $y(t)>0, \forall t \geq 0$ (since $E_{0}$ and $E_{w}$ are repulsive). Thus, $z$ tends to $\gamma^{-1}$, which shows the absence of periodic solutions or cycles. Therefore, any trajectory converges to an equilibrium point. The previous studies of equilibria and local stability allow us to conclude for the different cases.

The asymptotic behavior of System (4) is illustrated on Figures 1 and 2 for the different cases. The control law is robust whenever all the stable equilibrium lead to a productivity greater or equal to $\mathcal{P}_{1}$ (see Table 1 ).

Restriction to more realistic cases. In order to restrict our analysis to a more realistic case, we consider a subset of $S$ more relevant from an ecological point of view. We consider that each parameter represents a trait that is involved in the fitness of the species. A species with the best values for each trait will outcompete all the other species in any environmental conditions, and such super mutant should not exist. Actually, one may assume tradeoffs between the different traits. For $m$ traits, we consider that the $m$ archetypes (or specialist, i.e. a species with the best value for one trait and the worst values for the others) define a Pareto front where all the species lie [Shoval et al. 2012]. In our example, we consider three archetypes $x_{\bar{\mu}}$, $x_{K}, x_{\alpha}$, with:

$$
\begin{aligned}
\theta_{\bar{\mu}} & =\left(\bar{\mu}^{+}, K^{+}, \alpha^{-}\right) \\
\theta_{K} & =\left(\bar{\mu}^{-}, K^{-}, \alpha^{-}\right) \\
\theta_{\alpha} & =\left(\bar{\mu}^{-}, K^{+}, \alpha^{+}\right)
\end{aligned}
$$

Note that the best value for $K$ is $K^{-}$. These archetypes define the subset $\bar{S}$ :

\footnotetext{
1 note that we ignore subsets of null measure corresponding to nongeneric cases, since they will never appear in practice (for example the cases $s^{*}=s_{c}$, or $s_{2}^{*}=s_{c}$ ).
} 

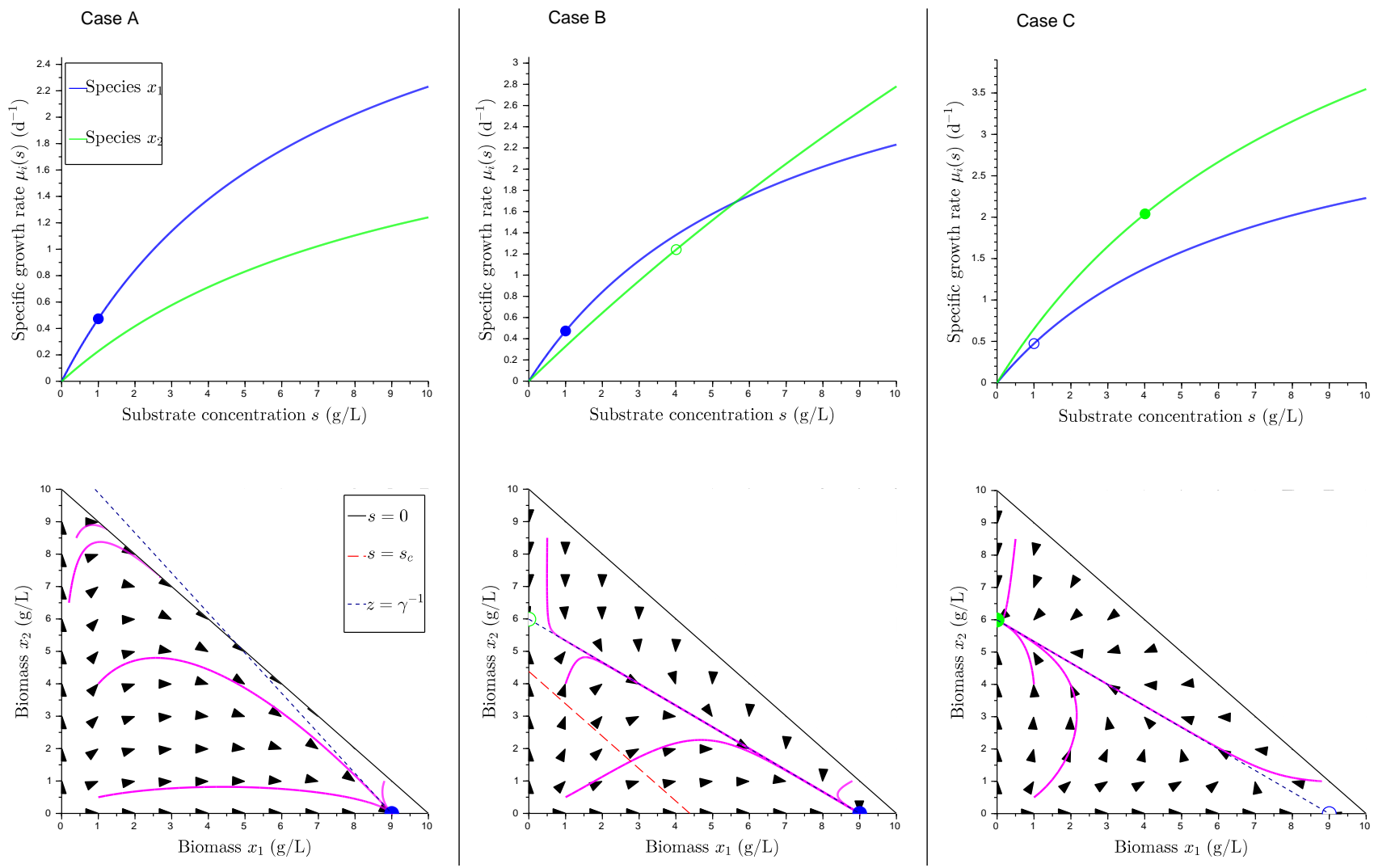

Fig. 1. Asymptotic behavior of System (4), Case A-C (see Proposition 5 and Table 1). Top: Specific growth rates as a function of substrate concentration. Bottom: Phase portraits with some trajectories (in purple). Filled circle: stable equilibrium, blank circles: unstable equilibrium. Blue: species $x_{1}$, green: species $x_{2}$, red: coexistence.

Table 1. Equilibrium and robustness for System (4) (see Proposition 5)

\begin{tabular}{|c|c|c|c|c|c|c|c|}
\hline Case & Conditions & $E_{0}$ & $E_{w}$ & $E_{1}$ & $E_{2}$ & $E_{c}$ & Robustness \\
\hline A & $\neg \mathrm{C} 1$ & LS & uns & - & no & - & $\mathrm{F}$ \\
\hline B & C1.C4. $(\neg \mathrm{C} 5)$ & uns & uns & GS & uns & no & $\mathrm{T}$ \\
\hline $\mathrm{C}$ & $\mathrm{C} 1 .(\neg \mathrm{C} 4) . \mathrm{C} 5$ & uns & uns & uns & GS & no & $\mathrm{T}$ iff $\mathcal{P}_{2}=\mu_{2}\left(s_{2}^{*}\right)\left(s_{i n}-s_{2}^{*}\right) \geq \mathcal{P}_{1}$ \\
\hline $\mathrm{D}$ & C1. $(\neg \mathrm{C} 4) \cdot(\neg \mathrm{C} 5)^{a}$ & uns & uns & uns & uns & GS & $\mathrm{T}$ iff $\mathcal{P}_{c}=\mu_{1}\left(s_{c}\right)\left(s_{i n}-s_{c}\right) \geq \mathcal{P}_{1}$ \\
\hline $\mathrm{E}$ & C1.C4.C $5^{b}$ & uns & uns & LS & LS & uns & $\mathrm{T}$ iff $\mathcal{P}_{2}=\mu_{2}\left(s_{2}^{*}\right)\left(s_{\text {in }}-s_{2}^{*}\right) \geq \mathcal{P}_{1}$ \\
\hline
\end{tabular}

$\bar{S}:=\left\{\theta=a \theta_{\bar{\mu}}+b \theta_{K}+c \theta_{\alpha}, \forall(a, b, c) \in[0,1]^{3} \mid a+b+c=1\right\}$

Thus, for any triplet $\left(a_{i}, b_{i}, c_{i}\right) \in[0,1]^{3} \mid a_{i}+b_{i}+c_{i}=1$, the parameter vector of the species $x_{i}\left(a_{i}, b_{i}, c_{i}\right)$ is given by:

$$
\theta_{i}=\left(\begin{array}{c}
a_{i} \bar{\mu}^{+}+\left(1-a_{i}\right) \bar{\mu}^{-} \\
b_{i} K^{-}+\left(1-b_{i}\right) K^{+} \\
c_{i} \alpha^{+}+\left(1-c_{i}\right) \alpha^{-}
\end{array}\right)
$$

The morphospace, i.e. the space of trait values, is represented on a ternary plot in Figure 3. Each vertex of the triangle represents an archetype. We consider Control law (3) designed for a species $x_{1}(0.4,0.3,0.3)$ located near the center of the morphospace. After discretizing the morphospace, we test for each additional species which conditions (C1, C4, C5) hold in order to determine the asymptotic behavior of the system (see Proposition 5 and Table 1). This allows us to define $S_{R}$ (represented in color on Figure 3), a subset of $\bar{S}$, such that Control law (3) is $\left(S_{R}, 1, \mathcal{P}\right)$ robust.
First, one can see that the presence of an additional species can increase the productivity. On the other hand, the control law is not robust for a large subsets of $\bar{S}$, corresponding mainly to an additional species with a smaller yield coefficient than species $x_{1}\left(\alpha_{2}<\alpha_{1}\right)$. Two situations may occur: the productivity at a stable equilibrium point $\left(E_{2}\right.$ or $E_{c}$ ) is smaller than the productivity $\mathcal{P}_{1}$, or there is a reactor shutdown ( $s$ and $y$ converge towards zero). A small decrease in productivity can actually be tolerated (although it is not considered in the present definition of multispecies robustness). On the other hand, the reactor shutdown is much more problematic and represents a real drawback of Control law (3). Anyway, parameter $\gamma$ can be tuned in order to avoid as far as possible such situation, i.e. to increase the robustness to biodiversity of the control law.

The study of robustness for $n$ species is obviously more delicate and is now under investigation. 

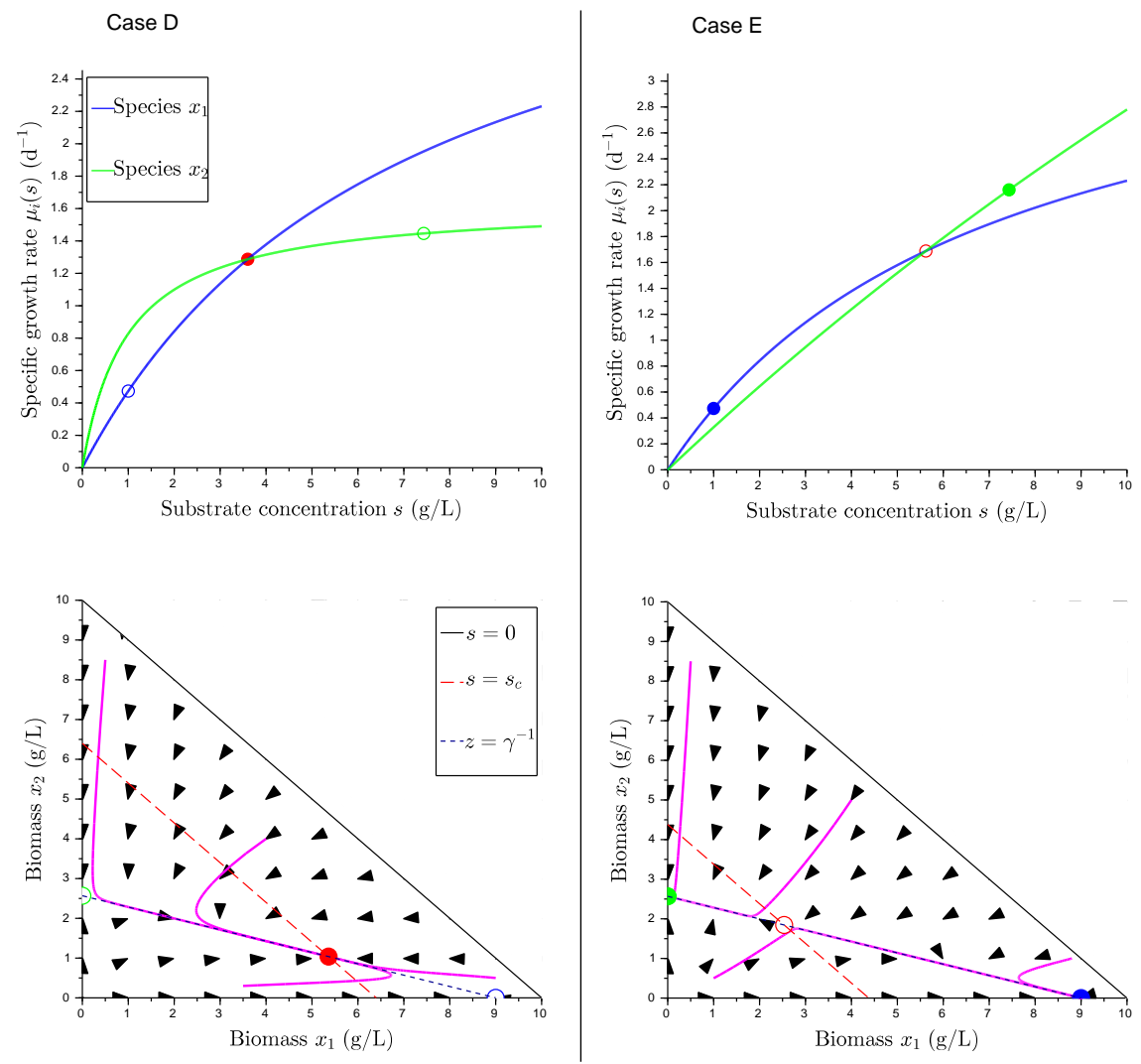

Fig. 2. Asymptotic behavior of System (4), Case D-E (see Proposition 5 and Table 1). Same legend as Figure 1.

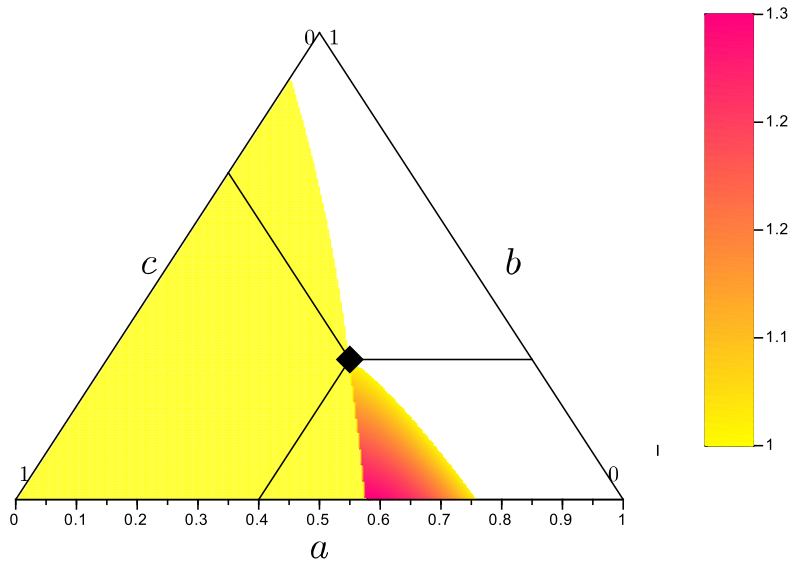

Fig. 3. Robustness of Control law (3) on a ternary plot of the morphospace $\bar{S}$. Each vertex represents an archetype: $x_{\bar{\mu}}(1,0,0), x_{K}(0,1,0), x_{\alpha}(0,0,1)$. The diamond represents species $x_{1}(0.4,0.3,0.3)$. The set of species $S_{R}$, such that Control law $(3)$ is $\left(S_{R}, 1, \mathcal{P}\right)$ robust, is represented in color. The color map represents the relative increase of productivity (with respect to $\left.\mathcal{P}_{1}\right)$.

\section{DISCUSSION}

The robustness with respect to parametric uncertainty is classically studied for bioprocess control laws. Here, we have defined the multispecies robustness. These two approaches are clearly not equivalent. Actually, the $n$ species can be seen as one species with time-varying kinetic and stoechiometric parameters. Such time-varying aspect is generally not considered in parametric uncertainty. Moreover, the multispecies robustness also involves species competition/selection/coexistence. These phenomena, which affect bioprocess productivity, are not considered in the robustness with respect to parametric uncertainty.

\subsection{Link with species competition}

The classical theory of species competition [Smith and Waltman 1995] does not apply when the chemostat is operated with a closed loop control, and some surprises can arise. For example, if we consider a slow growing species $x_{2}$ (with $\mu_{2}(s)<\mu_{1}(s), \forall s \in\left(0, s_{i n}\right)$ ), we expect that this species will rapidly be outcompeted (as it happens in open loop), so it should not affect the asymptotic behavior of the system. Actually, with Control law (3), the substrate depletion equilibrium $E_{0}$ can become locally stable in presence of $x_{2}$ (if $\alpha_{2} \gamma s_{i n}<1$ ), so this species can cause reactor shutdown (see Figure 1, Case A).

\subsection{Coexistence of two species}

The stable coexistence of two species is possible whenever their specific growth rates intersect. In open loop, this is not possible in practice since the dilution should be chosen exactly equal to the rate at which growth curves intersect. On the other hand, De Leenheer and Smith [2003] have proposed a feedback control for the stable coexistence of two species. Assuming increasing growth 
rates and measurement of both biomass concentrations $x_{1}$ and $x_{2}$, the feedback $u=c_{1} x_{1}+c_{2} x_{2}+\epsilon$ (where $c_{1}, c_{2}$, and $\epsilon$ are constant which should be chosen such that some conditions hold) globally stabilizes the system towards a coexistence point. Gouzé and Robledo [2005] have extended this approach for non-monotone growth rates with only the measurement of the sum of biomass concentrations $x_{1}+x_{2}$. In both studies, the original system is gathered in a planar competitive system. This allows to exclude the existence of periodic solution using PoincaréBendixson Theorem. Here, we have shown that the feedback law (3) can also lead to stable coexistence. In this case, we obtain a planar system which is not competitive (and neither cooperative). A change of coordinate (System (13)) is used to show the absence of periodic solution. To guarantee stable coexistence for two species with this control law, one must choose the set-point $s^{*}$ accordingly. Assuming without loss of generality $\mu_{1}^{\prime}\left(s_{c}\right)>\mu_{2}^{\prime}\left(s_{c}\right)$, the coexistence point $E_{c}$ is globally asymptotically stable iff $\alpha_{1}>\alpha_{2}$ and $0<s_{2}^{*}<s_{c}<s^{*}<s_{i n}$. This last condition is fulfilled whenever on choose $s^{*} \in\left(s^{*}, \overline{s^{*}}\right)$, where

$$
\begin{aligned}
& \underline{s^{*}}=\max \left\{s_{c}, s_{i n}\left(1-\alpha_{2} / \alpha_{1}\right)\right\}, \\
& \overline{s^{*}}=\min \left\{s_{i n}, s_{i n}\left(1-\alpha_{2} / \alpha_{1}\right)+s_{c}\right\} .
\end{aligned}
$$

If $\alpha_{1}<\alpha_{2}$, Control law (3) does not allow stable coexistence.

\subsection{Challenges}

Maintaining a high bioreactor productivity despite invasive species (or new individuals resulting from natural mutations) turns out to be a challenging problem to ensure process robustness. New questions arise now, such as detecting and preventing the apparition of "bad species". Observers could be set-up to early identify new competing species with reduced productivity capability. Control strategies, such as extremum-seeking [Guay et al. 2004], could be adapted in order to consider multispecies and maintain conditions favorable for the settlement of mote productive species. As demonstrated in this paper, such control strategies could use this opportunity to continuously improve the reactor performance.

\section{CONCLUSION}

We have introduced the concept of multispecies robustness for bioprocess control laws. We have illustrated our approach with a control law proposed in Mailleret et al [2004]. Depending on the characteristics of the additional species, some counter-intuitive results may appear such as coexistence, or even reactor shutdown when a slowgrowing species is introduced. This framework should be used to design multispecies robust control laws and therefore better tame biodiversity within a biotechnological process.

\section{REFERENCES}

Bastin, G. and Dochain, D. (1990). On-line estimation and adaptive control of bioreactors. Elsevier, New York.

Bayen, T. and Mairet, F. (2014). Optimization of the separation of two species in a chemostat. Automatica. doi: http://dx.doi.org/10.1016/j.automatica.2014.02.024. Available online.
De Leenheer, P. and Smith, H. (2003). Feedback control for chemostat models. Journal of Mathematical Biology, 46(1), 48-70.

Dochain, D. (2008). Automatic control of bioprocesses. John Wiley \& Sons, Inc.

Gajardo, P., Ramirez C., H., and Rapaport, A. (2008). Minimal time sequential batch reactors with bounded and impulse controls for one or more species. SIAM Journal on Control and Optimization, 47(6), 2827-2856.

Gouzé, J.L. and Robledo, G. (2005). Feedback control for nonmonotone competition models in the chemostat. Nonlinear Analysis: Real World Applications, 6(4), 671690.

Guay, M., Dochain, D., and Perrier, M. (2004). Adaptive extremum seeking control of continuous stirred tank bioreactors with unknown growth kinetics. Automatica, 40(5), 881-888.

Karafyllis, I., Kravaris, C., Syrou, L., and Lyberatos, G. (2008). A vector lyapunov function characterization of input-to-state stability with application to robust global stabilization of the chemostat. European Journal of Control, 14(1), 47-61.

Mailleret, L., Bernard, O., and Steyer, J.P. (2004). Robust nonlinear adaptive control for bioreactors with unknown kinetics. Automatica, 40:8, 365-383.

Mairet, F., Muñoz-Tamayo, R., and Bernard, O. (2013). Driving species competition in a light-limited chemostat. In 9th IFAC Symposium on Nonlinear Control Systems (NOLCOS).

Mazenc, F., Malisoff, M., and Harmand, J. (2008). Further results on stabilization of periodic trajectories for a chemostat with two species. IEEE Transactions on Automatic Control, 53, 66-74.

Perrier, M., de Azevedo, S.F., Ferreira, E., and Dochain, D. (2000). Tuning of observer-based estimators: theory and application to the on-line estimation of kinetic parameters. Control Engineering Practice, 8(4), 377388.

Ramirez, I., Volcke, E.I., Rajinikanth, R., and Steyer, J.P. (2009). Modeling microbial diversity in anaerobic digestion through an extended adm1 model. Water research, 43(11), 2787-2800.

Sbarciog, M. and Vande Wouwer, A. (2012). Some considerations about control of multi-species anaerobic digestion systems. In Proceedings of the 7th Vienna International Conference on Mathematical Modelling (MATH$M O D)$. Vienna, Austria.

Shoval, O., Sheftel, H., Shinar, G., Hart, Y., Ramote, O., Mayo, A., Dekel, E., Kavanagh, K., and Alon, U. (2012). Evolutionary trade-offs, pareto optimality, and the geometry of phenotype space. Science, 336(6085), 1157-1160.

Smith, H.L. and Waltman, P. (1995). The theory of the chemostat: dynamics of microbial competition. Cambridge University Press. 